\title{
Contribution of the Ventral Subiculum to Inhibitory Regulation of the Hypothalamo-Pituitary-Adrenocortical Axis
}

\author{
James P. Herman ${ }^{1}$, William E. Cullinan², Maria Ines Morano², Huda Akil ${ }^{2}$ and Stanley J. Watson ${ }^{2}$ \\ ${ }^{1}$ Department of Anatomy and Neurobiology, University of Kentucky School of Medicine, Lexington, KY 40536-0084, USA. \\ ${ }^{2}$ Mental Health Research Institute, University of Michigan, Ann Arbor, MI 48109-0720, USA. \\ Key words: paraventricular nucleus, glucocorticoids, corticotropin releasing hormone, vasopressin, mRNA, ibotenic acid, stress.
}

\begin{abstract}
Anatomical studies indicate that the ventral subiculum is in a prime position to mediate hippocampal inhibition of the hypothalamopituitary-adrenocortical (HPA) axis. The present study evaluated this hypothesis by assessing HPA function following ibotenic acid lesion of the ventral subiculum region. Rats with lesions of the ventral subiculum (vSUB) or ventral hippocampus (vHIPPO) did not show changes in basal corticosterone (CORT) secretion at either circadian peak or nadir time points when compared to sham-lesion rats (SHAM) or unoperated controls. However, rats with vSUB lesions exhibited a prolonged glucocorticoid stress response relative to all other groups. Baseline CRH mRNA levels were significantly increased in the medial parvocellular paraventricular nucleus (PVN) of the vSUB group relative to controls. $\mathrm{CRH}$ mRNA differences were particularly pronounced at caudal levels of the nucleus, suggesting topographic organization of vSUB interactions with PVN neurons. Notably, the vHIPPO group, which received large lesions of ventral CA1, CA3 and dentate gyrus without significant subicular damage, showed no change in stress-induced CORT secretion, suggesting that the ventral subiculum proper is principally responsible for ventral hippocampal actions on the HPA stress response. No differences in medial parvocellular PVN AVP mRNA expression were seen in either the vSUB or vHIPPO groups. The results indicate a specific inhibitory action of the ventral subiculum on HPA activation. The increase in CRH biosynthesis and stress-induced CORT secretion in the absence of changes in baseline CORT secretion or AVP mRNA expression suggests that the inhibitory actions of ventral subicular neurons affect the response capacity of the HPA axis.
\end{abstract}

The organismic stress response is mediated by the integrated action of a variety of sensory and associational brain circuits on discrete populations of neuroendocrine neurons. The primary cell population responsible for activation of the stress response is comprised of parvocellular neurons of the hypothalamic paraventricular nucleus (PVN) $(1,2)$. In response to stressful stimuli, these neurons are cued to release secretagogues for $\mathrm{ACTH}$, the most prominent of which are corticotropin releasing hormone $(\mathrm{CRH})$ and arginine vasopressin (AVP), into the pituitary portal circulation. These factors eventually promote release of glucocorticoids at the adrenal. Changes in plasma glucocorticoids then act by way of the brain to provide a negative feedback signal to the HPA axis $(3,4)$, serving to inhibit further release of ACTH and thereby limit the magnitude and duration of the stress response.

Adequate control of HPA secretion is crucial for maintenance of homeostasis. Hypersecretion of glucocorticoids causes numerous hormonal and metabolic abnormalities (see (5)). Furthermore, glucocorticoid imbalances have been implicated in the pathogenesis of depression and in age-related cognitive decline (6-8). The effects of glucocorticoid hypersecretion on mood and perhaps cognition may ultimately stem from disturbed glucocort- icoid negative feedback regulation by the hippocampus. The literature suggests that the hippocampus plays a role as a primary negative modulator of hypothalamo-pituitary-adrenal (HPA) axis activation (see (9)). Hippocampal ablation or disconnection results in hypersecretion of corticosterone (CORT) and $A C T H$, up-regulation of PVN CRH and AVP mRNA expression, and increased secretion of CRH and AVP into portal blood (9-15), all of which are consistent with an inhibitory role for this structure in HPA regulation. In addition, hippocampal damage appears to prolong the CORT response to an acute stressor and decrease the ability of exogenous glucocorticoids to inhibit a stress response $(10,16,17)$, implicating this structure as an integrative site for negative feedback regulation of the HPA axis.

Our previous lesion studies have indicated that a strong inhibitory influence on CRH and AVP mRNA expression is carried in efferent fibers from ventral hippocampus (15). The ventral hippocampus is rich in type 1 and type 2 glucocorticoid receptors $(18-20)$ and appears to have disynaptic interactions with stressintegrative neurons of the PVN (21). Together, these data strongly suggest a prominent role for this region in inhibitory HPA regulation. The present studies were therefore designed to deter-

Correspondente to: Dr James P. Herman. Department of Anatomy and Neurobiology, University of Kentucky Medical Center, 800 Rose Street, Lexington, KY 40536-0084, USA. 
mine the involvement of neuronal elements in the ventral hippocampus on regulation of ACTH secretagogue biosynthesis and the glucocorticoid stress response.

\section{Results}

To determine the role of ventral hippocampal structures in HPA regulation, parameters of HPA function were examined following selective destruction of ventral hippocampal neurons using the excitatory amino acid neurotoxin ibotenic acid. Injections of neurotoxin into the ventral subiculum caused significant damage to the vast majority of the ventral subiculum, some ventral regions of CA1 and limited portions of CA3 and dentate gyrus (DG) (Fig. 1). Lesions were centered at the middle of the rostrocaudal extent of the ventral subiculum, and typically destroyed the vast majority of the structure. However, in all cases there was some degree of sparing of cells located at the rostral and/or caudal extremes of the subiculum. To differentiate potential sequelae of ventral subiculum damage from cell loss in neighboring ventral hippocampal structures, additional ibotenic acid injections were centered dorsal to the ventral subiculum. These ventral hippocampal lesions (vHIPPO) involved ventral CA1, CA3 and DG while sparing the majority of neurons present in the region of the ventral subiculum (Fig. 1). In no case did animals included in the vHIPPO or vSUB groups show significant damage to the amygdala or amygdalohippocampal transition zone.

The effects of hippocampal lesions of plasma corticosterone (CORT) levels are presented in Fig. 2. Overall ANOVA revealed a significant interaction between group and time on CORT secretion $(F(3,9)=3.34, P<0.01)$. As can be seen from Fig. $2 A$, no lesion resulted in significant elevation of plasma glucocorticoids under basal conditions, nor did any lesion alter the peak corticosterone secretion seen $30 \mathrm{~min}$ following stress. However, plasma corticosterone levels were significantly elevated at $60 \mathrm{~min}$ following stress in the vSUB group relative to saline-injected (SHAM) and unoperated control (CON) animals $(\mathrm{P}<0.05$,
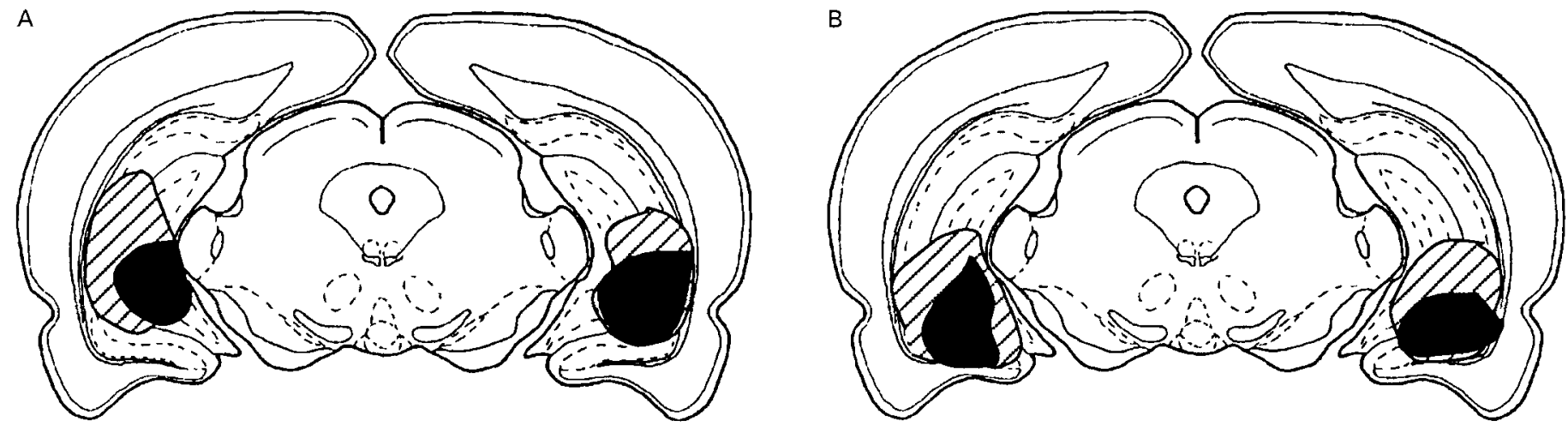

FIG. 1. Schematics illustrating the largest (stipple fill) and smallest (black fill) bilateral ibotenic acid lesions of the ventral hippocampus (A) and ventral subiculum (B). Note that while both lesions destroyed a comparable amount of hippocampal tissuc, the ventral subiculum lesions extended more ventrally and involved all of the lateral and most of the medial component of the subiculum, whereas ventral hippocampal lesion spared this region.
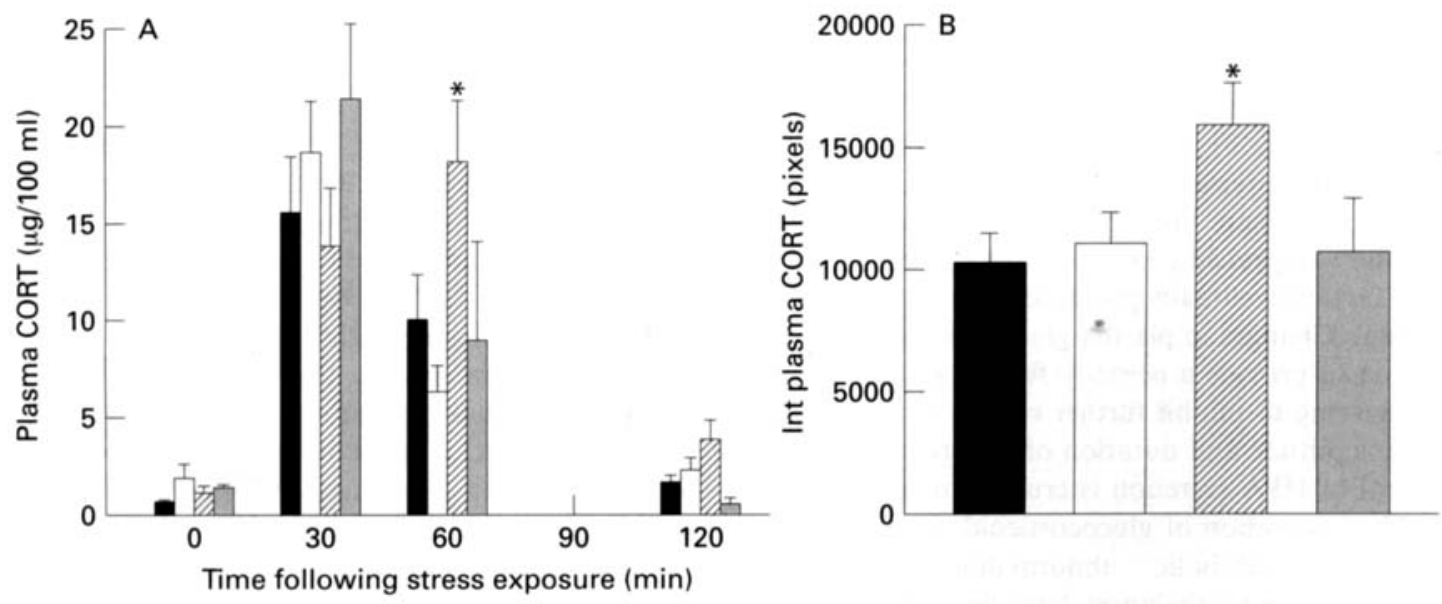

FIG. 2. Plasma corticosterone (CORT) level following acute restraint stress $(30 \mathrm{~m})$. A. Note that all rats showed a robust stress response at 30 min post-stress, which abated to near baseline levels by $2 \mathrm{~h}$ after induction of restraint $(90 \mathrm{~min}$ following removal from restraint cages). Primary differences are observed at the 60 min time point ( 30 min following removal from restraint cages), where plasma CORT levels were significantly elevated in the VSUB group relative to ventral hippocampal lesion (VHIPPO), sham-lesion (SHAM) or unoperated control (CONTROL) rats. B. Determination of area under the CORT-response curve for all subjects revealed significant increases (40-50\%) in the integrated CORT response of the vSUB group relative to all CONTROL, SHAM and vHIPPO rats. The CORT data was amassed from experiments 2 and 3 , and included a total of 11 CON, 14 SHAM, 5 vHIPPO and 12 vSUB animals. Error bars represent standard error of the mean. Control: $\square$ SHAM; $\mathbb{Z}$ vSUB: $\square$ vHIPPO. 
Duncan's Multiple Range test). vSUB rats did not differ from controls at the $120 \mathrm{~min}$ time point. Analysis of the integrated CORT response to restraint stress (area under the curve) (Fig. 2B) revealed a significant effect of group on the overall magnitude of stress-induced CORT secretion $(\mathrm{F}(3,35)=2.85, \mathrm{P}<0.05)$, highlighted by significant differences between the vSUB group and all others ( $\mathrm{P}<0.05$, Duncan's Multiple Range test). The vSUB group showed an overall increase of $40-50 \%$ in magnitude of the CORT response to the single stress episode.

In contrast to effects of vSUB lesion on the stress response, there was no effect of any lesion on plasma CORT level at times corresponding to peak and nadir levels of CORT secretion. Note that samples were collected from the same animals either two hours after lights on (AM) or one hour before lights off (PM) (Fig. 3). These data suggest that ventral subiculum does not directly affect baseline CORT secretion at either circadian peak or nadir time points. However, it should be noted that a lack of basal CORT change does not completely preclude the possibility

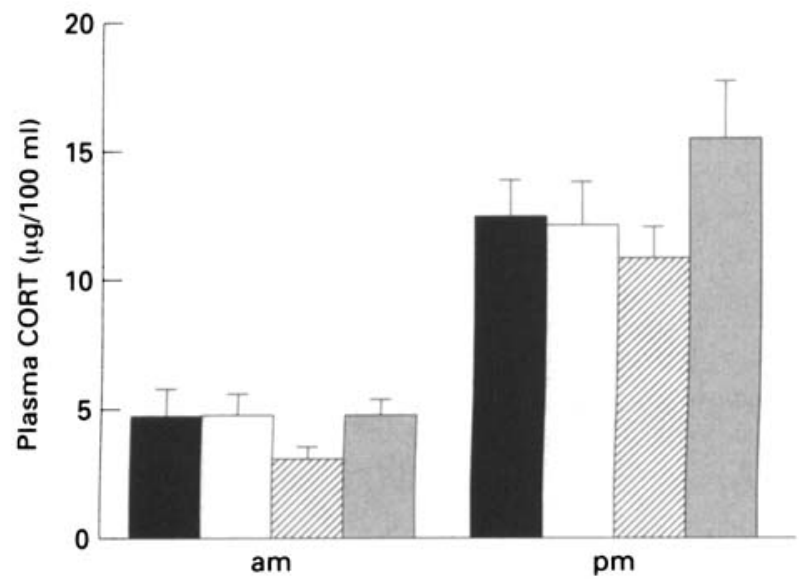

Fig. 3. Diurnal plasma CORT secretion, measured between $2-4 \mathrm{~h}$ after lights-on (am) and $1-2 \mathrm{~h}$ prior to lights-out $(\mathrm{pm})$. No differences could be detected among the four groups. A total of $10 \mathrm{CON}, 15 \mathrm{SAL}, 11$ vHIPPO and 11 vSUB animals were included in the data analysis. Circadian CORT data was collected from experiments 2 and 3 , and included a total of $11 \mathrm{CON}, 15$ SHAM, 6 vHIPPO and 12 vSUB animals. Error bars represent standard error of the mean. Control; $\square$ SHAM; V vSUB; 圆 vHIPPO.
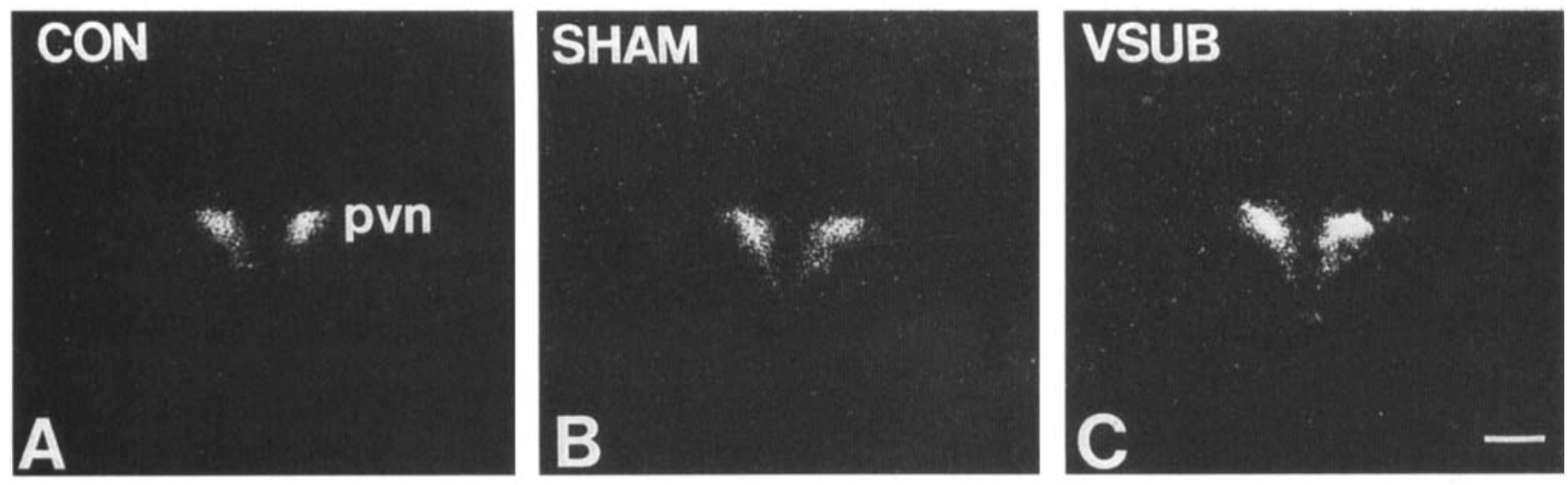

FIG. 4. Localization and regulation of CRH mRNA expression in the medial parvocellular paraventricular nucleus of unoperated control (CON), sham lesion (SHAM) and ventral subiculum lesion (vSUB) rats. Note increased CRH mRNA expression at this level of the nucleus in vSUB rats with respect to CON or SHAM. Magnification bar $=500 \mu \mathrm{m}$. 
478 Ventral subiculum and HPA regulation

of group on CRH mRNA content in the medial parvocellular PVN. Post-hoc analysis using Duncan's Multiple Range test revealed significant differences between the vSUB group and both SAL and CON groups, and between the vHIPPO group and the CON group $(P<0.05)$. One-way ANOVA of effects at the four defined anatomical levels indicated significant effects of group on CRH mRNA expression at rostrocaudal level $\mathrm{B}(\mathrm{F}(3,42)=3.87$, $\mathrm{P}<0.05)$ and $\mathrm{C}(\mathrm{F}(3,43)=5.32, \mathrm{P}<0.01)$; subsequent post-hoc analysis revealed significant differences between vSUB and CON at level B and D between vSUB and all groups at level $\mathrm{C}$ ( $P<0.05$, Duncan's Multiple Range test).

Expression of AVP mRNA in the medial parvocellular division of the PVN was determined by cell and grain counts. Parvocellular neurons were identified from Nissl-counterstained emulsiondipped sections, on the basis of localization in the medial parvocel- lular PVN and association of radioactive grains with identifiable parvocellular nuclei (see Fig. 6). In contrast with CRH mRNA, AVP mRNA expression was not significantly altered by any treatment (Fig. 7). There were no pronounced increase in either number of verified parvocellular neurons or in number of radioactive grains/cell in vSUB or vHIPPO rats relative to salineinjected or unoperated control groups.

\section{Discussion}

Previous work has suggested that the hippocampus has an inhibitory relationship with the HPA axis, in terms of stressedinduced ACTH and CORT secretion and baseline CRH and AVP mRNA expression $(9-11,13-15,17)$. The role of the hippocampus as a potential central negative feedback site has been rein-
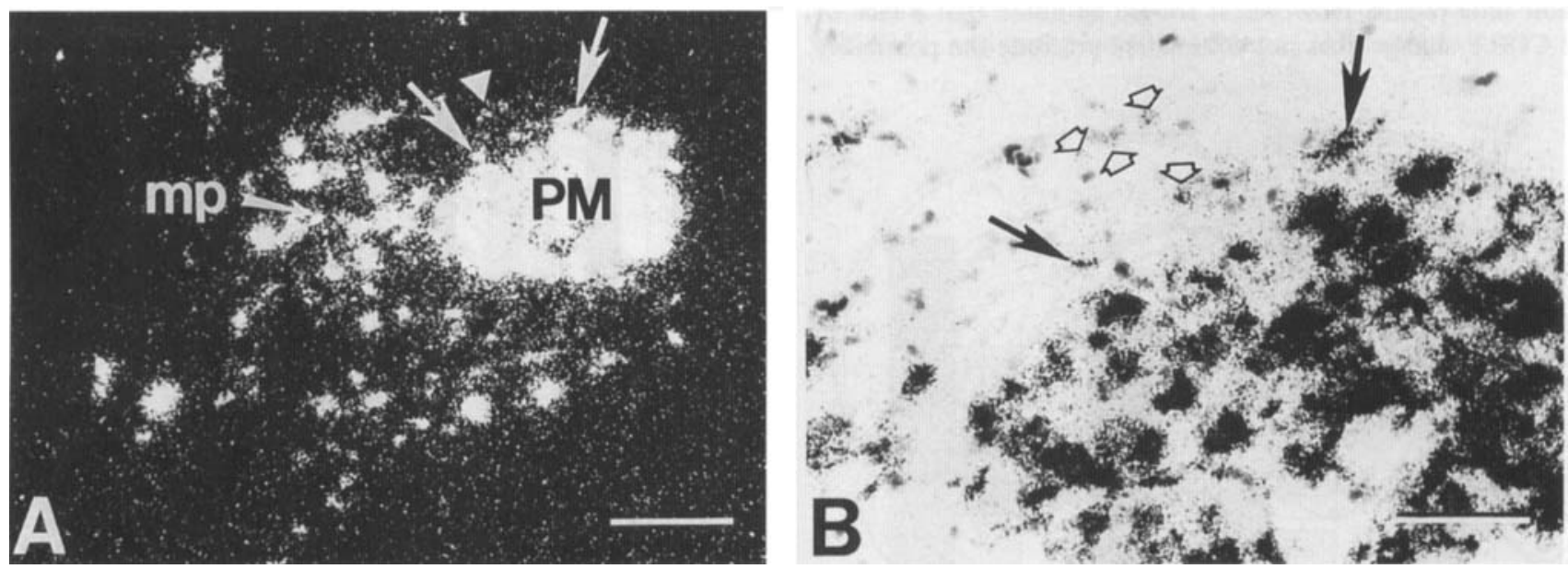

FIG. 6. Criteria used to define parvocellular AVP-containing neurons in the paraventricular nucleus. Arrow heads in A and $\mathrm{B}$ indicate several parvocellular neurons, distinguishable from magnocellular neurons indicated by large arrows. Criteria for identification as parvocellular neurons included: 1) localization in the medial parvocellular PVN, 2) a definable nucleus with parvocellular phenotype (approx. 5-8 $\mu \mathrm{m}$ diameter), and 3 ) grain aggregations exceeding 5 times background levels. Note the low density of radioactive grains relative to neighboring magnocellular neurons. mp $=$ medial parvocellular division of the PVN; $\mathrm{PM}=$ posterior magnocellular division of the PVN. Magnification bars $=100 \mu \mathrm{m}(\mathrm{A}) ; 25 \mu \mathrm{m}(\mathrm{B})$.
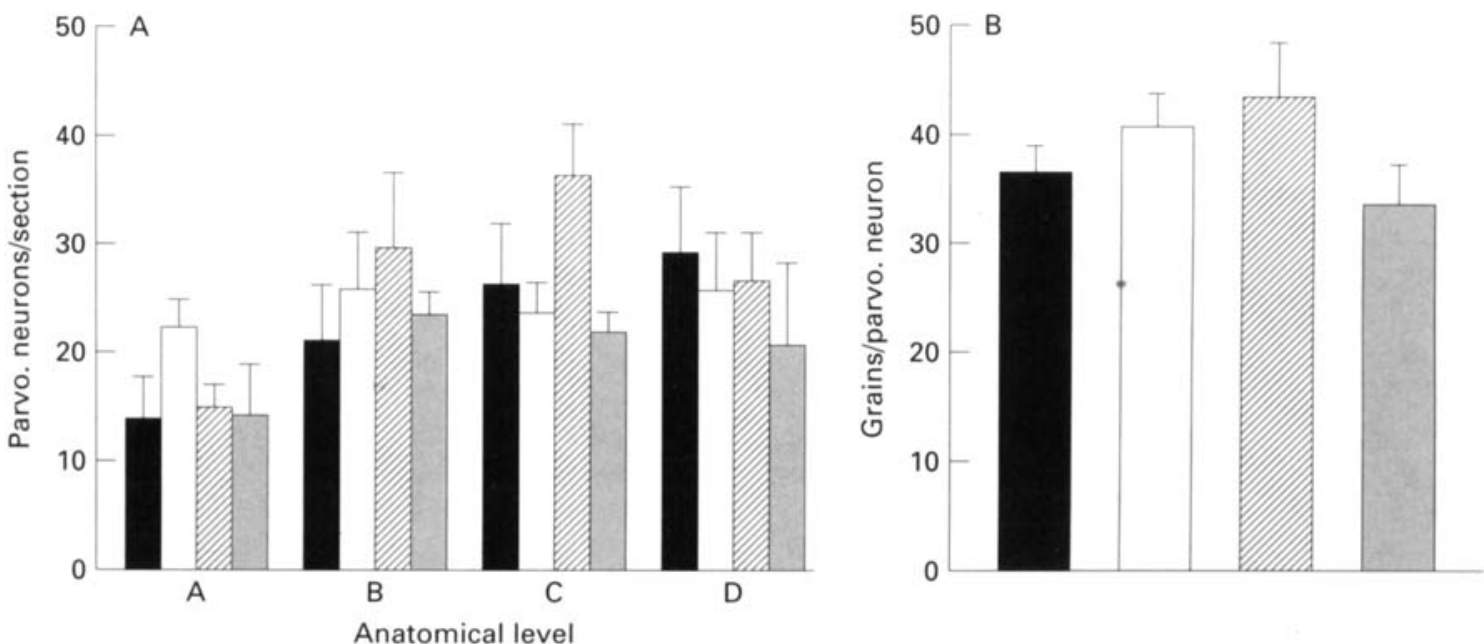

FIG. 7. Analysis of AVP mRNA expression in parvocellular neurons of the medial parvocellular PVN. No significant effect of group was seen on either the overall number of identifiable parvocellular neurons/section (A) or number of grains/parvocellular neuron (B). AVP mRNA data was collected from experiment 2, and included a total of 5 CON, 9 SAL, 5 vHIPPO and 5 vSUB animals. Error bars represent standard error of the mean. $\mathbf{D}$ Control; ᄃ SHAM: $\square$ VUB: 圆 vHIPPO. 
forced by the observation that this structure contains the highest levels of both type 1 and type 2 adrenocorticosteroid receptors in brain $(20,22)$. However, the neural circuits which convey such inhibitory influences are ill-defined. Neuroanatomical data indicate that hippocampal efferents to the region of the PVN emanate primarily from the ventral subiculum (23-25). Subicular efferents do not appear to synapse directly with the parvocellular PVN; rather, these neurons terminate in a number of regions, including the bed nucleus of the stria terminalis, preoptic area and mediobasal hypothalamus, which in turn connect to the PVN $(21,25)$. Ventral subiculum efferents to these basal forebrain and hypothalamic structures are conveyed by two distinct and perhaps equally important pathways. The first pathway uses the fimbria-fornix system to project to basal forebrain and hypothalamic structures. The second pathway takes a ventrolateral course out of the ventral subiculum, traverses the amygdala and projects to forebrain structures by way of the stria terminalis (21). The present investigation was designed to test the effects of removal of both pathways on parameters of HPA activity by specifically targeting the cells of origin. Unlike hippocampectomy or fornix lesion, this approach preserves the majority of hippocampal neurons and hippocampal afferent fibers, minimizing indirect effects of extraneous hippocampal damage on HPA activity.

In the present experiments, we demonstrate that focal damage to the ventral subiculum results in significant prolongation of the CORT response to an acute stressor. Enhancement of the stress response was not observed in animals bearing ventral hippocampal lesions sparing the ventral subiculum, indicating that the secretory changes seen in the ventral subiculum group were not due to ancillary damage to ventral CA1, CA3 or dentate gyrus. Effects of ventral subiculum damage on secretion appears to be specific for the stress response, as peak and nadir CORT levels are unaffected by ventral subiculum lesion.

A number of previous studies have documented prolongation of the glucocorticoid stress response following hippocampal damage or fimbria-fornix section in rat and monkey $(9,11)$. However, other reports do not support these observations, indicating no action of fimbria-fornix lesion or hippocampal damage on glucocorticoid secretion $(9,26)$. The lack of concordance seen in the literature may stem in large part from variations in extent of lesion. We have shown that neurons of the ventral subiculum may project from the hippocampal formation by either the fimbria-fornix or by a ventrolateral pathway which traverses the amygdaloid complex (and thence projects to forebrain regions by way of the stria terminalis). The latter projection is particularly intriguing in this regard, since the extent of stria terminalis damage caused by fimbria-fornix lesion, total hippocampectomy and dorsal hippocampectomy varies from study to study, dependent in large part upon lesion technique. Indeed, Bradbury and colleagues note that their lesions did not impinge on the stria terminalis at all, raising the possibility that the lack of observable effects seen in their study may relate to sparing of subicular efferents using this pathway (26). In combination with the present report, these observations appear to indicate that hippocampal effects on the HPA stress response involve efferents using both the fimbria-fornix and stria terminalis, or indeed the stria terminalis alone. However, we cannot discount the possibility that physiological effects observed in this study were due to disruption of subicular efferents traversing or synapsing in the amygdaloid complex.
The lack of change in circadian pattern of CORT secretion stands in contrast to previous reports demonstrating disruption of circadian CORT secretion following ventral subiculum steroid implants (27) or lesion of the lateral fimbria fornix (28). Our study sampled only two time points, and it is therefore possible our analysis missed times during the day when CORT secretion indeed deviated from the norm. However, it should also be noted that rats with fimbria-fornix transections show disruption of circadian CORT secretion one but not three weeks post-surgery (29), suggesting the capacity for recovery of circadian function following hippocampal disconnection. Our experiments were performed two weeks post-surgery, raising the possibility that functional recovery of basal patterns of CORT secretion may have occurred over this period. It should also be acknowledged that our lesions may not have been large enough to obliterate hippocampal influences on circadian drive, or that interactions with circadian rhythms may employ temporal lobe structures spared by our lesions.

The observed prolongation of stress-induced CORT secretion resembles, but does not completely mimic, secretory changes seen in aged animals. Previous studies have repeatedly shown that aged Fischer 344 rats show prolonged secretion of CORT in response to restraint (30-32). However, whereas vSUB rats show increased CORT secretion only at the $60 \mathrm{~min}$ post-stress time point, secretion in aged rats is elevated for up to $4 \mathrm{~h}(30-32)$. The connection, if any, between the ventral subiculum and agerelated glucocorticoid hypersecretion remains to be evaluated.

Ventral subiculum ablation results in a significant increase in steady-state CRH mRNA levels. The observed changes in $\mathrm{CRH}$ mRNA expression are greater at caudal levels of the PVN, suggesting either a topographic input to the PVN or differential activation of subpopulations of $\mathrm{CRH}$ neurons. The former explanation appears more probable, as our lesions could not encompass the entire rostrocaudal extent of the ventral subiculum region. It should also be noted that the overall percent increase seen in VSUB animals ( $150 \%$ of operated control at affected levels of the PVN) is less than that observed following lateral fimbriafornix lesion (175-190\% of operated control) (15) or total or dorsal hippocampectomy (200\% of operated control) (14). The smaller effect seen in the present study again suggests that bilateral vSUB lesion does not eliminate all hippocampal inhibition of CRH mRNA expression. Thus, surviving neurons at the poles of the ventral subiculum or in neighboring cell groups may be playing a role in limiting the magnitude of $\mathrm{CRH}$ mRNA up-regulation seen in the present report.

Ventral subiculum damage does not significantly increase parvocellular vasopressin mRNA expression. Our previous work has shown a slight AVP up-regulation following lateral fimbria-fornix lesion, and a trend toward an increase following total hippocampectomy $(14,15)$. The lack of a reliable parvocellular AVP mRNA increase may reflect the incompleteness of the ibotenic acid lesions. For example, $\mathrm{CRH}$ mRNA expression was highest at posterior levels of the PVN; in like fashion, AVP mRNA leveis tended to be higher at level $\mathrm{C}$ of the PVN. The lack of noticeable effects at more anterior levels may thus be associated with sparing of ventral subicular cells influencing AVP expression. Alternatively, the lack of significant AVP mRNA change may be associated with methods of quantitative analysis. The single-cell analysis used in the present experiments relies on rigorous identification of medial parvocellular neurons prior to cell and grain 
counting. This strategy provides quite conservative estimates, eliminating any grain aggregations not definitively associated with a distinctly parvocellular nucleus. Our previous studies $(14,15)$ had used a densitometric analysis strategy, which by its nature incorporates signal generated by all grains in the sampled area. including () aggregations of grains which did not exceed five times background grain density and 2) grains from sources not associated with distinct cellular profiles.

The lack of increase in baseline parvocellular AVP mRNA expression may also be related to the nature of the vasopressinergic contribution to HPA activation. Under normal conditions, AVP mRNA and peptide expression in the medial parvocellular PVN is quite low. Induction of AVP expression in parvocellular PVN neurons typically occurs upon acute or chronic stimulation of the HPA axis, by either stress or glucocorticoid depletion (33-38). In the present study, there is little evidence for pronounced baseline activation of the HPA axis; indeed, in ventral subiculum lesion rats baseline glucocorticoid secretion is normal. Thus, in animals killed under unstressed conditions it is reasonable to expect normal or near-normal AVP expression; effects of ventral subiculum neurons on AVP expression may require stimulation of the PVN.

Together, increases in baseline CRH mRNA and stress-induced CORT secretion are consistent with a tonic disinhibition of PVN CRH neurons. Up-regulation of baseline CRH mRNA expression suggests increased biosynthesis of CRH. Increases in cellular $\mathrm{CRH}$ would be predicted to underlie the increase in stress-induced CORT secretion, as an augmentation in releasable $\mathrm{CRH}$ may promote increases in the amount ACTH released per stressful episode, resulting in a greater overall glucocorticoid response. The up-regulation of $\mathrm{CRH}$ may be due to a loss of glucocorticoid negative feedback control mediated by ventral subiculum neurons, which are known to be glucocorticoid receptive $(20)$, and/or to loss of a stress-integrative circuit which may (or may not) use glucocorticoids as a control element. Note that while vSUB lesion affects stress-induced CORT release, no effects are evident on basal morning or evening release. The lack of lesion-induced change in basal CORT levels suggests that the postulated increases in $\mathrm{CRH}$ biosynthesis may not be sufficient to elicit up-regulation of ACTH secretion under basal release conditions. Alternatively, lesion-induced increases in ACTH release may decrease adrenal sensitivity, resulting in a compensatory normalization in adrenal CORT secretion.

While the evidence presented indicates that the ventral subiculum plays a role in mediation of stress-induced CORT secretion, it is clearly not the only forebrain region to do so. For example, a recent report indicates a prominent action of the medial prefrontal cortex on post-restraint inhibition of both ACTH and CORT secretion (39). Lateral septal damage also has the capacity to prolong stress-induced CORT secretion in response to immobilization stress (40). Conversely, lesion of the amygdaloid central nucleus and anterolateral divisions bed nucleus of the stria terminalis decrease CRH mRNA expression and ACTH release induced by restraint stress or conditioned fear (41-43). Notably, all these forebrain regions, whether inhibitory or excitatory to the HPA axis, contain one or both adrenocorticosteroid subtypes (20) and are thus targets for actions of secreted glucocorticoids.

The literature clearly indicates that numerous forebrain regions act to modulate HPA stress responses. We hypothesize that structures such as the hippocampus, prefrontal cortex, amygdala and septum work in concert to modulate stress sensitivity by: 1) tuning the predisposition of PVN neurons to secrete in response to a given stimulus, 2) altering the net effect of glucocorticoid negative feedback on PVN neurons, or 3 ) interacting with central associative pathways controlling interpretation of stimulus significance. Along these lines, we predict that lesion of the ventral subiculum increases HPA tone by removal of an inhibitory component of this generalized forebrain stress system. It remains to be determined whether this component is linked directly to secreted steroids.

\section{Materials and methods}

\section{Subjects}

Subjects were male Sprague-Dawley rats, weighing between $250-350 \mathrm{~g}$ at the time of surgery. Animals were housed $6 / \mathrm{cage}$, and were maintained in a constant temperature/humidity quarters on a $12: 12 \mathrm{~h}$ light : dark cycle.

\section{Surgery}

Lesions were made using injection of the excitatory neurotoxin ibotenic acid. All rats were anesthetized with $0.6 \mathrm{ml} / 100 \mathrm{~g}$ body weight of a $7 \%$ chloral hydrate solution and mounted into a David Kopf stereotaxic apparatus. The scalp was then incised and holes drilled through the skull at points overlying injection coordinates. In injected animals, a $1 \mu \mathrm{l}$ Hamilton syringe was lowered into place and allowed to remain undisturbed for $5-10 \mathrm{~m}$, and $250-400 \mathrm{nl}$ of either $10 \mu \mathrm{g} / \mu \mathrm{l}$ ibotenic acid (in phosphate-buffer saline, $\mathrm{pH} 7.4$ ) or sterile saline was injected over a $10 \mathrm{~min}$ period, at the end of which syringes were left in place for an additional $5-10 \mathrm{~min}$. This procedure was then repeated on the contralateral side. Coordinates for ventral subiculum lesion were determined from the Paxinos and Watson atlas (44); injections were positioned at $5.8 \mathrm{~mm}$ posterior to bregma, $4.2 \mathrm{~mm}$ on each side of midline and $7.4 \mathrm{~mm}$ ventral to the dural surface.

\section{Experimental Protocols}

\section{Experiment 1}

Ibotenic acid and saline injections into the ventral subiculum were performed as outlined above, with an additional group of rats serving as unoperated controls. Animals were allowed to recover for 10 days. Animals were then sacrificed by rapid decapitation between the hours of 08.30 and 10.30. Brains were removed and frozen in isopentane cooled to -40 to $-50^{\circ} \mathrm{C}$ on dry ice, and core blood collected in heparinized tubes for subsequent analysis of plasma corticosterone

\section{Experiment 2}

To provide detail on patterns of CORT secretion in vSUB lesion rats, additional groups of rats were given saline or ibotenic acid injections, as above, within a third group serving as unoperated controls. Operated animals were allowed to recover from surgery for 10 days, at which point stress testing was initiated. Testing consisted of exposing animals to a 30 min placement in Plexiglas restraint tubes. Blood was sampled by tailnick within $60 \mathrm{~s}$ of placement into restraint tubes (referred to henceforth as time 0), $30 \mathrm{~min}$ following restraint, $60 \mathrm{~min}$ following restraint, and $120 \mathrm{~min}$ following restraint. All animals were replaced in their home cages at $30 \mathrm{~min}$, thus, at the 60 and $120 \mathrm{~min}$ time points rats were removed from their cages, lightly restrained and blood sampled within $60 \mathrm{~s}$ of retrieval. Two days following stress testing, blood samples were taken by tail-nick at $16.00-17.00$ ( $1 \mathrm{~h}$ before lights off $)$. Rats were lightly restrained during this process, and blood was sampled within $60 \mathrm{~s}$ of removal from their home cages. Rats were allowed 4 days recovery, and were then sacrificed as above. Animals were killed between 08.00 and 09.00 , and core blood collected for baseline AM CORT determinations.

\section{Experiment 3}

Experiment 2 pointed toward altered stress responsivity in ventral subiculum lesion rats. To verify changes in post-stress glucocorticoid secretion seen in experiment 2 , an additional series of rats was processed to replicate the principal finding. Stress testing was initiated 10 days following surgery, 
and was accomplished as outlined above. Data from experiments 2 and 3 were pooled for analysis.

\section{In situ hypridization}

Brains were removed from the $-70^{\circ} \mathrm{C}$ freezer and sectioned on a BrightHacker cryostat $(-18$ to $-20 \mathrm{C}) .15 \mu \mathrm{m}$ sections were collected throughout the rostrocaudal extent of the PVN, and $20 \mu \mathrm{m}$ sections through the lesion sites. For in situ hybridization. sections were removed from the freezer and immediately immersed in cold $4^{\prime \prime}$ " paraformaldehyde for $30 \mathrm{~min}$. Tissues were rinsed $2 \times$ in nanopure water and $2 \times$ in $2 \times$ SSC. and were then placed in prewarmed $0.2 \mu \mathrm{g} / \mathrm{ml}$ protcinase $\mathrm{K}$ solution (in $10 \mathrm{mM}$ Tris $\mathrm{pH} 8.0,5 \mathrm{mM}$ EDTA). Sections were incubated in proteinase $\mathrm{K}$ for $15 \mathrm{~min}$ at $37^{\circ} \mathrm{C}$, at which point they were rinsed for $1 \mathrm{~min}$ in nanopure water and $1 \mathrm{~min}$ in $0.1 \mathrm{M}$ tricthanolamine, $\mathrm{pH} 8.0$. Acetic anhydride was then added to the triethanolamine buffer to a final concentration of $0.25^{\circ} \%$, and the incubation continued for $10 \mathrm{~min}$. Tissue was then rinsed in $2 \times \mathrm{SSC}$ for $5 \mathrm{~min}$ and dehydrated through graded alcohols.

Antisense ${ }^{35}$ S-labeled cRNA probes were synthesized for rat $\mathrm{CRH}$ (760 bp BamHI fragment, subcloned in pGem3, directed at the 3' extreme of the protein coding region and the $3^{\prime}$ untranslated (UT) region) (courtesy R.C. Thompson. University of Michigan. MI, USA) and rat AVP exon $C$ ( $229 \mathrm{bp}$ fragment subcloned in pGem4, complementary to AVP exon $C$ and $3^{\prime}$ untranslated sequences and specific for vasopressin). All probes were produced using standard in vitro transcription. Plasmids containing subcloned CDNAs were linearized with the appropriate 5 '-overhang producing restriction enzyme to yield probes of desired length and $\mathrm{G}: \mathrm{C}$ composition. Labeling reactions included $1 \mu \mathrm{g}$ linearized plasmid. $1 \times$-SP6 transcription buffer (Bethesda Research Labs), $250 \mu \mathrm{Ci}$ ${ }^{a}{ }^{35}$ S-UTP ( $>1000 \mathrm{Ci} /$ mmole, dried; Amersham), $150 \mu \mathrm{M}$ ATP, $150 \mu \mathrm{M}$ CTP, $150 \mu \mathrm{M}$ GTP, $12.5 \mathrm{mM}$ dithiothreitol, $3.0 \mathrm{u}^{\prime} / \mu \mathrm{l}$ RNAsin (Promega) and $0.5 \mathrm{u} / \mu \mathrm{SP} 6$ or T7 RNA polymerase (Boeringher-Mannheim). The reaction was incubated for $90 \mathrm{~min}$ at $37^{\circ} \mathrm{C}$, and the labeled probe separated from free nucleotide over a Sephadex G50-50 column.

${ }^{35}$ S-labeled cRNAs probes were diluted in hybridization buffer $\left(50^{\prime \prime}\right.$, formamide, $10 \%$ dextran sulfate, $3 \times$-SSC, $50 \mathrm{mM}$ sodium phosphate buffer. $\mathrm{pH} 7.4,1 \times$ Denhardt's, $0.1 \mathrm{mg} / \mathrm{ml}$ yeast tRNA and $0.1 \mathrm{mg} / \mathrm{ml}$ sheared salmon sperm DNA) in such a manner as to yield a final concentration of $1,000,000 \mathrm{dpm} / 30 \mu \mathrm{l}$. Aliquots of $30 \mu \mathrm{I}$ were applied to each slide and the sections coverslipped. Adjacent hypothalamic sections were hybridized with probes complementary to rat CRH or AVP mRNAs. All slides were incubated overnight at $55^{\circ} \mathrm{C}$ in sealed plastic boxes containing moistened foam. Coverslips were then removed, the slides rinsed in $2 \times-$ SSC and immersed in fresh $2 \times-\mathrm{SSC}$ for $20 \mathrm{~min}$. The tissue was treated with RNAse $\mathrm{A}(100 \mu \mathrm{g} / \mathrm{ml})$ at $37^{\circ} \mathrm{C}$ for $30 \mathrm{~min}$ to degrade any remaining single-stranded cRNA and washed successively in $2 x-$, $1 \times$ - and $0.2 \times$-SSC for $10 \mathrm{~min}$ cach, followed by a $60 \mathrm{~min}$ wash in $0.2 \times$ SSC at $65^{\circ} \mathrm{C}$. Sections were dehydrated through alcohols and exposed to Kodak XAR X-ray film and subsequently. Kodak NTB2 nuclear emulsion.

\section{Image and 1 isis}

Semi-quantitative analyses of in situ hybridization autoradiographs were conducted utilizing Macintosh-based Image software (courtesy Wayne Rasband. NIH. USA). Sections from ibotenic acid lesion. saline injected and control animals were matched for rostrocaudal level. CRH determinations in PVN were made from digitized X-ray autoradiographs, with the level of the nucleus delineated on the basis of adjacent Nissl-counterstained sections. The parvocellular PVN was divided into four bins, using the Paxinos and Watson coordinate system (44) as a guide. With respect to Bregma, level A corresponded to approximately $-1500 \mu \mathrm{m}$, level B $-1650 \mu \mathrm{m}$, level $\mathrm{C}-1800 \mu \mathrm{m}$ and level $\mathrm{D}-1950 \mu \mathrm{m}$. All OD measures were corrected for background and multiplied by the area sampled. yielding intcgrated $O D$ units. Mean values for all animals were determined from 3-12 sections representing all levels through the PVN. and mean values per level used in the subsequent analysis of group effects. AVP mRNA measurements were made from emulsion-dipped. Nisslcounterstained autoradiographs to permit clear delineation of medial parvocellular neurons. Parvocellular neurons were verified in counterstained sections on the basis of nuclear size and location, and were manually counted on sections from each of the four PVN levels. Positive cells: 1) exhibited clearly-definable aggregations of grains exceeding $5 x$ background, 2) were localized in the medial parvocellular division of the
PVN, and 3) overlaid clearly definable single nuclei whose appearance was consistent with parvocellular PVN neurons. Grain aggregations in which nuclei could not be clearly delineated were not included in cell or grain counts. The criteria used to define parvocellular neurons are illustrated in Fig. 6.

Grain counts were performed using IMAGE software and a manual routine devised in this laboratory. Individual $40 \times$ fields from lightlycountcrstained slides were imaged under dark field illumination and were digitized in IMAGE using a Data Translation video capture card interfaced with a Macintosh Quadra 700 computer. Images were gray-level threshold-adjusted to allow measurement of pixels corresponding to grains and omit pixels corresponding to counterstain. Once set. this threshold was retained for the duration of the experiment. Mean grain size was established at $40 \times$ magnification by sequential sampling of 15 regions within a representative image. The area occupied by grains in each region was calculated, and divided by the number of visible grains present within the region to reveal mean grain size. For sampling. illumination was switched to bright field and appropriate parvocellujar neurons delineated on the basis of relation to apparent parvocellular nuclci. Grains corresponding to identified cells were then delineated on the corresponding dark-illuminated field. This procedure insured accurate assessment of parvocellular neurons while effectively factoring out the influence of the counterstain. The area occupied by grains in the sampled area was then divided by the mean grain size to arrive at raw grains per cell; total grains per cell was determined by subtracting from this number the number of grains calculated from equivalent non-specifically hybridized areas. During the progress of the grain-counting protocol, manual counts were periodically performed on representative cells for comparison to the semiautomated procedure. Manual counts were highly corrclated to automated measure $(\mathrm{r}=0.87)$, and did not differ significantly from them (mean manual grains $/$ cell $=32.1 \pm 5 . \mathrm{I}$; mean automated grains $/$ cell $=31.8 \pm 6.3$ ). Approximately 8-10 parvocellular neurons were counted per animal, with all counted cells clearly localized to the dorsolateral medial parvocellular PVN at rostrocaudal levels $B$ and $C$.

\section{Hormone assuys}

For plasma corticosterone measurement, aliquoted samples ( $5 \mathrm{ml}$ ) from each animal were extracted with chloromethane to eliminate endogenous transcortin. After evaporation of the solvent, the plasma was resuspended in radioimmunoassay buffer. Recoveries of $[3 \mathrm{H}]$ corticosterone through the whole procedures were higher than $90 \%$.

Corticosterone was assayed by radioimmunoassay using a rabbit antiserum ( B3a) raised against B-21-hemisuccinate : BSA (courtesy E. Estivariz and M.I. Morano). This antiserum, used at a final titer of 1:4000, crossreacts $2^{\circ}$ o with cortisol and deoxycorticosterone and less than $0.3^{\circ} \%$ with progestrone. estradiol, testosterone or aldosterone. [3H] corticosterone was used as tracer. The detection limit of the assay was 1 pg of corticosterone, and the intra- and inter-assay coefficients of variation were $2 \%$ and $3^{\circ} \%$, respectively.

Area under the curve was used as a measure of the integrated corticosterone response to stress. Areas were determined by generating graphs of mean corticosterone secretion us time for each rat. exporting these graphs to Image and measuring the total pixels under each curve by manual sampling.

\section{Data analysis}

For statistical analysis, all within-group analyses were performed by oneway ANOVA. followed by post hoc analysis (Duncan's Multiple Range test). Between-groups analysis was performed by two-way ANOVA, with groups again distinguished by post-hoc analysis. Stress timc-course data was analyzed by repeated measures one-way ANOVA.

\section{Acknowledgements}

This research was supported by MH49698 (J.P.H.). DA054542 (W.E.C.), MH42251 (S.J.W.) and a grant from the University of Kentucky Research Fund.

Accepted 20 April 1995 


\section{References}

1. Antoni FA. (1986). Hypothalamic control of adrenocorticotropin secretion: Advances since the discovery of 41-residue corticotropinreleasing factor. Endocrine Rev. 7: 351-378.

2. Whitnall MH. (1993). Regulation of the hypothalamic corticotropinreleasing hormone neurosecretory system. Prog Neurobiol. 40: 573-629.

3. Keller-Wood M, Dallman MF. (1984). Corticosteroid inhibition of ACTH secretion. Endocrine Rev. 5: 1-24.

4. Levin N. Shinsako J, Dallman MF. (1988). Corticosterone acts on the brain to inhibit adrenalectomy-induced adrenocorticotropin secretion. Endocrinology. 122: 694-701.

5. McEwen BS, Stellar E. (1993). Stress and the individual. Mechanisms leading to disease. Arch Intern Med. 153: 2093-101.

6. Carroll BJ, Curtis GC, Mendels J. (1976). Neuroendocrine regulation in depression, I: limbic system-adrenocortical dysfunction. Arch Gen Psychiatry. 33: 1039-1044.

7. Sapolsky RM. (1992). Stress, the Aging Brain, and the Mechanism of Neuron Death. MIT Press. Cambridge.

8. Sapolsky RM, Krey LC. McEwen BS. (1986). The neuroendocrinology of stress and aging: the glucocorticoid cascade hypothesis. Endocr Rev. 7: $284-301$.

9. Jacobson L. Sapolsky RM. (1991). The role of the hippocampus in feedback regulation of the hypothalamo-pituitary-adrenocortical axis. Endocrine Rev. 12: 118-134.

10. Sapolsky RM, Krey LC, McEwen BS. (1984). Giucocorticoidsensitive hippocampal neurons are involved in terminating the adrenocortical stress response. Proc Natl Acad Sci USA. 81: 6174-6177.

11. Sapolsky RM, Zola-Morgan S, Squire LR. (1991). Inhibition of glucocorticoid secretion by the hippocampal formation in the primate. J Neurosci. 11: 3695-3704.

12. Sapolsky RM, Armanini MP, Sutton SW. Plotsky PM. (1989). Elevation of hypophysial portal concentrations of adrenocorticotropin secretagogues after fornix transection. Endocrinology. 125: 2881-2887.

13. Sapolsky RM, Armanini MP, Packan DR, Sutton SW, Plotsky PM. (1990). Glucocorticoid feedback inhibition of adrenocorticotropic hormone secretagogue release. Relationship to corticosteroid receptor occupancy in various limbic sites. Neuroendocrinology. 51: 328-36.

14. Herman JP. Schäfer MK-H, Young EA, Thompson R, Douglass J, Akil H. Watson SJ. (1989). Evidence for hippocampal regulation of neuroendocrine neurons of the hypothalamo-pituitary-adrenocortical axis. J Neurosci. 9: 3072-3082.

15. Herman JP, Cullinan WE, Young EA, Akil H, Watson SJ. (1992). Selective forebrain fiber tract lesions implicate ventral hippocampal structures in tonic regulation of paraventricular nucleus CRH and AVP mRNA expression. Brain Res. 592: 228-238.

16. Feldman S, Confronti N. (1980). Participation of the dorsal hippocampus in the glucocorticoid feedback effect on adrenocortical activity. Neuroendocrinology. 30: 52-61.

17. Magarinos AM. Somoza G, DeNicola AF. (1987). Glucocorticoid negative fcedback and glucocorticoid receptors after hippocampectomy in rats. Horm Metab Res. 19: 105-159.

18. Ahima RS, Harlan RE. (1990). Charting of type II glucocorticoid receptor-like immunoreactivity in the rat central nervous system. Neuroscience. 39: 579-604.

19. Ahima RS. Krozowski Z. Harlan RE. (1991). Type I corticosteroid receptor-like immunoreactivity in the rat CNS: Distribution and regulation by corticosteroids. J Comp Neurol. 313: 522-538.

20. Herman JP. (1993). Regulation of adrenocorticosteroid receptor mRNA expression in the central nervous system. Cell Mol Neurobiol. 13: $349-372$.

21. Cullinan WE, Herman JP, Watson SJ. (1993). Ventral subicular interaction with the hypothalamic paraventricular nucleus: Evidence for a relay in the bed nucleus of the stria terminalis. $\mathbf{J}$ Comp Neurol. 332: $1-20$.

22. Reul JM, deKloet ER. (1985). Two receptor systems for corticosterone in rat brain: microdistribution and differential occupation. Endocrinology. 117: 2505-11.

23. Silverman A-J, Hoffman DL. Zimmerman EA. (1981). The descending afferent connections of the paraventricular nucleus of the hypothalamus. Brain Res Bull. 6: 47-61.

24. Berk ML, Finkelstein JA. (1981). Afferent projections to the preoptic area and hypothalamic regions in the rat brain. Neuroscience. 6: $1601-1624$

25. Sawchenko PE, Swanson LW. (1983). The organization of forebrain afferents to the paraventricular and supraoptic nuclei of the rat. J Comp Neurol. 218: 121-144.

26. Bradbury MJ, Strack AM, Dallman MF. (1993). Lesions of the hippocampal efferent pathway (fimbria-fornix) do not alter sensitivity of adrenocorticotropin to feedback inhibition by corticosterone in rats. Neuroendocrinology. 58: 396-407.

27. Slusher MA. (1966). Effects of cortisol implants in the brainstem and ventral hippocampus on diurnal corticosteroid levels. Exp Brain Res. 1: $184-194$

28. Fischette CT, Komisaruk BR, Edinger HM, Feder HH, Siegel A. (1980). Differential fornix ablations and the circadian rhythmicity of adrenal corticosteroid secretion. Brain Res. 195: 373-387.

29. Moberg GP, Scapagnini U, deGroot J, Ganong WF. (1971). Effect of sectioning the fornix on diurnal fluctuation in plasma corticosterone levels in the rats. Neuroendocrinology. 7: 11-5.

30. Morano MI, Vazquez DM, Akil H. (1994). The role of the hippocampal mineralocorticoid and glucocorticoid receptors in the hypothalamopituitary-adrenal axis of the aged Fischer rat. Mol Cell Neurosci. 5: $400-412$

31. Issa AM, Rowe W, Gauthicr S, Meaney MJ. (1990). Hypothalamicpituitary-adrenal activity in aged, cognitively impaired and cognitively unimpaired rats. J Neurosci. 10: 3247-3254.

32. Sapoisky RM, Krey LC, McEwen BS. (1983). The adrenocortical stress response in the aged rat: Impairment of recovery from stress. Exp. Gerontol. 18: 55-64.

33. Sawchenko PE, Swanson LW, Vale WW. (1984). Co-expression of corticotropin-releasing factor and vasopressin immunoreactivity in parvocellular neurosecretory neurons of the adrenalectomized rat. Proc Natl Acad Sci USA. 81: 1883-1887.

34. Sawchenko PE, Arias CA, Mortrud MT. (1993). Local tetrodotoxin blocks chronic stress effects on corticotropin-releasing factor and vasopressin messenger ribonucleic acids in hypophysiotropic neurons. J Neuroendocrinol. 5: 341-348.

35. Herman JP, Sherman TG. (1993). Acute stress upregulates vasopressin gene expression in parvocellular neurons of the hypothalamic paraventricular nucleus. Ann NY Acad Sci. 689: 546-549.

36. Schafer MK-H, Herman JP, Watson SJ. (1989). In situ hybridization analysis of gene expression in the HPA stress axis: Regulation by glucocorticoids. In: Ottoson D, Rostene W, (eds), Visualization of Brain Function, 11-22. The Macmillan Press, London, UK.

37. Kiss JZ, Mezey E, Skirboll L. (1984). Corticotropin-releasing factorimmunoreactive neurons of the paraventricular nucleus become vasopressin positive after adrenalectomy. Proc. Natl Acad Sci USA. 81: 1854-1858.

38. Bartanusz V. Aubry J-M, Jezova D, Baffi J, Kiss JZ. (1993). Up-regulation of vasopressin mRNA in paraventricular hypophysiotrophic neurons after acute immobilization stress. Neuroendocrinol. 58: $625-629$.

39. Diorio D, Viau V. Meaney MJ. (1993). The role of the medial prefrontal cortex (cingulate gyrus) in the regulation of hypothalamopituitary-adrenal responses to stress. J Neurosci. 13: 3839-3847.

40. Dobrakovova M, Kvetnansky R, Torda T. (1982). Changes of plasma and adrenal catecholamines and corticosterone in stressed rats with septal lesions. Physiol Behav. 29: 41-45.

41. Gray TS, Piechowski RA, Yracheta JM, Rittenhouse PA, Bethea CL, Van de Kar LD. (1993). Ibotenic acid lesions in the bed nucleus of the stria terminalis attenuate conditioned stress-induced increases in prolactin. ACTH and corticosterone. Neuroendocrinology. 57: 517-524.

42. Herman JP, Cullinan WE, Watson SJ. (1994). Involvement of the bed nucleus of the stria terminalis in tonic regulation of paraventricular hypothalamic $\mathrm{CRH}$ and AVP mRNA expression. $\mathbf{J}$ Neuroendocrinol. 6: $433-442$.

43. Prewitt CM, Herman JP. (1994). Lesion of the central nucleus of the amygdala decreases basal $\mathrm{CRH}$ mRNA expression and stress-induced ACTH release. Ann NY Acad Sci. 746: 438-440.

44. Paxinos G, Watson C. (1986). The Rat Brain in Stereotaxic Coordinates (2nd ed.). Academic Press. New York. 